\title{
Considerações sobre gestão da humanização hospitalar: o caso do Hospital Universitário da Universidade de São Paulo
}

Considerations on the management of hospital humanization: the case of the University Hospital of Universidade de São Paulo

Consideraciones sobre la gestión de la humanización hospitalaria: el caso del Hospital Universitario de la Universidad de São Paulo

Maria Aparecida da Silva Rodrigues

- $\quad$ Especialista em Gestão da Humanização em Serviços de Saúde pela Escola de Educação Permanente do Hospital das Clínicas da Faculdade de Medicina da USP (HC-FMUSP)

- $\quad$ Especialista em Gestão Estratégica em Comunicação Organizacional e Relações Públicas pela Escola de Comunicações e Artes da Universidade de São Paulo (ECA-USP)

- Especialista em Psicologia Hospitalar em Hospital Geral pelo Hospital das Clínicas da Faculdade de Medicina da USP (HC-FMUSP)

- Graduada em Psicologia pelo Centro Universitário das Faculdades Metropolitanas Unidas (UniFMU)

- Coordenadora do Serviço de Humanização do Hospital Universitário da USP (HU-USP)

- E-mail:crodrigues@hu.usp.br

\section{Izabel Cristina Rios}

- Doutora em Ciências pela Faculdade de Medicina da Universidade de São Paulo (FMUSP)

- Coordenadora do Núcleo Técnico e Científico de Humanização do Hospital das Clínicas da USP (HC-FMUSP)

- Médica, graduada pela Faculdade de Medicina da USP (FMUSP)

- Professora do Departamento de Medicina Legal, Ética Médica, Medicina Social e do Trabatho da FMUSP

- E-mail: izarios@usp.br 


\section{Resumo}

0 artigo apresenta a experiência da gestão da humanização no Hospital Universitário da Universidade de São Paulo, a importância do trabalho desenvolvido em rede e os resultados de um estudo de caso realizado no período de 2011 a 2014. A proposta é refletir sobre o conceito da humanização na área da saúde pública e a relevância da busca de parcerias que possam contribuir com a qualidade do trabalho desenvolvido. 0 primeiro passo nesse sentido foi identificar as relações que podem ser estabelecidas entre conceitos e técnicas da humanização na área da saúde e a interface com conceitos e técnicas da administração contemporânea e da comunicação institucional. No âmbito da investigação científica ou da atuação profissional, a área da comunicação é uma grande aliada, mas continua sendo um campo a ser explorado pela área da saúde, já que os desafios são muitos e bastante complexos.

\section{PALAVRAS CHAVE: HUMANIZAÇÃO • ADMINISTRAÇÃO • COMUNICAÇÃO • BENCHMARKING •IMAGEM • REPUTAÇÃO.}

\section{Abstract}

The article presents the experience of humanization management at the University Hospital of Universidade de São Paulo, the importance of the network developed work and the outcomes of a case study carried out from 2011 to 2014. The proposal is to assess the concept of humanization in the area of public healthcare and the relevance of seeking for partnerships that can contribute to the quality of the developed work. The first step taken in this direction was to identify the relations that can be established between humanization concepts and techniques in the healthcare area and the interface with contemporary administration and institutional communication concepts and techniques. The communication area is a great ally within the scope of scientific research or professional activity, but it is still an underexplored field for the healthcare area, with many and very complex challenges.

\section{KEYWORDS: HUMANIZATION・ADMINISTRATION・COMMUNICATION・BENCHMARKING・IMAGE・REPUTATION.}

\section{Resumen}

El artículo presenta la experiencia de la gestión de la humanización en el Hospital Universitario de la Universidad de São Paulo, la importancia del trabajo en red y los resultados de un estudio de caso realizado en el período de 2011 a 2014 , cuyo objetivo es reflexionar sobre el concepto de humanización en el área de la salud pública y la relevancia en la búsqueda de asociaciones que pueden contribuir a la calidad de su trabajo. El primer paso en esta dirección fue identificar las relaciones que se pueden establecer entre los conceptos y las técnicas de humanización en los conceptos de salud y de interfaz con conceptos y técnicas de la administración contemporánea y la comunicación institucional. En el ámbito de la investigación científica o del área de trabajo profesional de la comunicación es un gran aliado, sin embargo, continúa siendo un campo para ser explorado por el área de la salud ya que los retos son muchos y bastante complejos. 
humanização no Hospital Universitário da Universidade de São Paulo (HU-USP) foi proposta como um processo de 1 mudança de cultura institucional, desta visando criar espaços de reflexão e diálogo sobre valores que permeiam as práticas institucionais, como também, possibilitar a desconstrução e reconstrução de conceitos sobre a humanização, resultando em estímulo à mudança de comportamento e atitude, ao longo de extenso período de maturação.

Na área da saúde o termo humanização, para os que têm pouca familiaridade com ele, frequentemente é percebido como uma crítica, apresentando-se como barreira, controle, levando a vários comportamentos de defesa expressos, por exemplo, em manifestações tais como: "Humanização para quê, não somos humanos?" Ou: "Somos desumanos, tratamos mal as pessoas?" Ou, ainda: "Já estão inventando moda." Por outro lado, há os que associam a humanização a atitude solidária, bondade, caridade, organização de festas, atividades lúdicas e entretenimento.

Assim, o ponto de partida para compreender como a humanização se representa na instituição é realizar um diagnóstico situacional no que se refere à humanização. Em um segundo momento, caso a instituição objetive desenvolver a humanização como política institucional, deverá apresentá-la e implantá-la mediante modelo de gestão institucional (Rios; Battistella, 2013, p. 4-8). Pulverizar as áreas com debates sobre conceitos, princípios, técnicas, dispositivos e a metodologia recomendada pelas políticas de humanização nacional e estadual é uma importante tarefa para ressaltar propósitos da humanização, tais como: aprimorar a qualidade no trabalho em saúde, na segurança do paciente, no relacionamento entre os atores institucionais, como também na rede de atenção à saúde como um todo.

A razão motivadora deste artigo é refletir sobre essa perspectiva da humanização, articulando o campo da saúde ao da administração contemporânea e da comunicação, em texto que trata de conceitos e técnicas para gestão da humanização e a comunicação relacional como principal aliada.

O objetivo geral é apresentar e refletir sobre a gestão da humanização em um hospital público no qual se desenvolveu um modelo de gestão da humanização compatível com os pressupostos apontados. Pretende-se: refletir sobre conceitos e técnicas para humanização; descrever e analisar dados referentes ao caso em estudo; apresentar o modelo de rede colaborativa adotado; e refletir sobre a utilização de indicadores em humanização.

0 método utilizado para esta reflexão foi o estudo de caso, com leitura exploratória de registro de documentos referentes ao desenvolvimento da humanização em um hospital público no período de 2011 a 2014 e análise interpretativa com subsídios de referências teóricas da literatura em saúde, administração e comunicação.

As considerações a que este estudo leva podem responder a um importante questionamento, relativamente à importância da humanização em instituições de saúde: a gestão da humanização em serviços de saúde pode auxiliar no fortalecimento da imagem positiva da instituição?

\section{POLÍTICA NACIONAL DE HUMANIZAÇÃO (PNH): MARCOS HISTÓRICOS}

Conforme Rios e Battistella $(2013$, p. 2) apontam, a política de humanização se refere a movimentos, conceitos e ações de diferentes origens históricas e linhas de pensamento sujeito a várias interpretações.

A humanização nasceu como política pública do Sistema Único de Saúde (SUS), em resposta aos reclames da sociedade. Várias iniciativas com os acordes da humanização surgiram, como, por exemplo, a luta antimanicomial, os movimentos feministas pela humanização do parto e nascimento (Rios, 2009). 
Em 2000, a XI Conferência Nacional de Saúde (CNS) abordou o tema "Acesso, qualidade e humanização na atenção à saúde com controle social", trazendo pela primeira vez o assunto para discussão nacional. No mesmo ano (2000) o Ministério da Saúde, sensível às manifestações setoriais e às diversas iniciativas locais de humanização das práticas da saúde, criou 0 Programa Nacional de Humanização da Assistência Hospitalar (PNHAH). Esse programa estimulava a disseminação das ideias da humanização, os diagnósticos situacionais e a promoção de ações humanizadoras de acordo com as realidades locais. 0 programa propôs atuação de forma transversal, subjetiva e de caráter processual. Estabeleceu como metas fundamentais aprimorar as relações entre os profissionais de saúde e os usuários e entre os próprios profissionais (Brasil, 2003).

Em 2003 o Ministério da Saúde fez uma revisão no PNHAH e lançou a Política Nacional de Humanização (PNH), que mudou o patamar de alcance da humanização dos hospitais para toda a rede SUS e definiu uma política cujo foco passou a ser, principalmente, os processos de gestão e de trabalho. A PNH está definida a partir dos princípios da transversalidade, da indissociabilidade entre atenção e gestão e do fortalecimento do protagonismo, da corresponsabilidade e da autonomia dos sujeitos e coletivos. Aumentou o grau de comunicação intra e intergrupos, favorecendo maior integração entre pessoas e grupos (Brasil, 2006).

Em 2012 foi lançada a Política Estadual de Humanização (PEH), que tem como tarefa adequar a proposta nacional à realidade do Estado de São Paulo, integrando e potencializando as ações de humanização já desenvolvidas. É de responsabilidade do estado, em conjunto com os municípios, formular e implementar política que valorize e fortaleça localmente os princípios, as diretrizes e os dispositivos propostos pela PNH (Governo, 2012).

Deslandes (2006, p. 35) afirma que "a humanização deve ser praticada nos serviços de saúde, com profissionais e usuários, de forma dialógica, em busca de uma construção de novos caminhos capazes de propiciar um novo paradigma de gestão da saúde pública".

Rios e Battistella (2013, p.3) abordam a humanização no ambiente organizacional ou institucional, dizendo q ue "é 0 conjunto de processos que visa transformar a cultura institucional por meio da construção coletiva de compromissos éticos e de métodos para as práticas de saúde e gestão dos serviços baseados na busca de soluções compartilhas por todos os envolvidos em tais ações".

Para Rodrigues (2012, p.186), um dos maiores desafios do modelo de gestão participativa é buscar um alinhamento das diversas instâncias institucionais, em locais em que predomina o modelo departamental e fragmentado, buscando um modelo de trabalho integrado, possibilitando uma visão do processo como um todo em busca de soluções compartilhadas.

Portanto, trata-se de promover uma política institucional com foco nos processos de gestão e de trabalho, a partir de diagnóstico situacional, e desenvolver ações planejadas e conjuntas com todos os envolvidos de forma dialógica, transversal e multidisciplinar, além de vislumbrar a busca por soluções mais criativas e colaborativas, ampliando o olhar do profissional para que se sinta integrante ativo no processo, possibilitando maior compromisso e responsabilidade com o bem comum.

Campos (2005, p. 400) ressalta que a humanização depende de mudança das pessoas, dando ênfase em valores ligados à defesa da vida, na possibilidade da ampliação do grau de desalienação e de transformar o trabalho em processo criativo e prazeroso.

A humanização na área da saúde propõe a gestão participativa, que, para seu desenvolvimento, requer ampliar o diálogo, integrando saberes por meio de conceitos e técnicas discutidas há décadas nos campos da administração e da comunicação. 


\section{ADMINISTRAÇÃO CONTEMPORÂNEA: ABORDAGEM HUMANÍSTICA}

A abordagem humanística da administração surgiu em oposição à teoria clássica da administração definida por Frederick Taylor, contrapondo-se a conceitos mecanicistas. Na década de 1930 a partir da Experiência Hawthorne, desenvolvida por Elton Mayo e colaboradores, marcou o início de uma nova teoria calcada em valores humanísticos na administração, deslocando a preocupação colocada na tarefa e na estrutura para a preocupação com as pessoas. Aparece, então, 0 interesse com fatores como motivação, comunicação, liderança, trabalho em equipe, em contraponto a outros fatores como autoridade, departamentalização, tarefas etc. Dessa forma, a abordagem humanística empregou um olhar mais atento às necessidades e características dos colaboradores, vendo-os mais na dimensão de seres humanos e menos na condição de empregados (Chiavenato, 2003, p. 97-99).

A partir de então, e estando a sociedade contemporânea em constante transformação, exigem-se constantes mudanças das organizações ou instituições, para adaptar-se às necessidades do mundo globalizado. Surgem, então, modelos de organização e administração moldados às novas realidades, movidos pela necessidade de inovação e renovação, pela busca de flexibilidade e adoção de novas ideias.

Nesse novo paradigma, Manuel Castells (1998, p. 192) aborda o modelo de organização flexível e ressalta que essa nova organização desce do pedestal da burocracia verticalizada para atuar em rede, organizar-se em torno de um processo, e não de uma tarefa, promover gestão em equipe, mensurar os resultados pela satisfação do cidadão.

Levando-se em consideração a organização aberta em rede, para aprimorar o relacionamento e a comunicação entre os serviços de saúde, resultando em maior eficiência na prestação de serviços à comunidade, ressaltamos a importância da comunicação.

\section{COMUNICAÇÃO ORGANIZACIONAL}

A comunicação é de vital importância para o bom desempenho das relações institucionais. Kunsch (2010, p. 9-12) ressalta que a tendência à humanização das relações das empresas com a sociedade e com os indivíduos se apresenta ao mesmo tempo como inevitável e desejável. Segundo a autora, o tema humanização anuncia uma nova era no contexto das organizações, como um paradigma emergente, sistêmico e complexo, que redesenha na organização espaços de diálogo e construção de significado para o trabalho que se realiza.

No contexto hospitalar, ela adquire contornos específicos no que se refere ao diálogo, à clareza das informações e à precisão com que estas são transmitidas, fazendo parte do conjunto de ações que caracterizam o cuidado em saúde. Por exemplo, a comunicação efetiva entre profissionais e destes com o usuário impacta diretamente na qualidade da atenção aos usuários, contribuindo para o sucesso terapêutico.

A comunicação está prevista na Política Nacional de Humanização, pois dependem dela a gestão participativa e 0 comprometimento de todos, profissionais e usuários, para o bom desenvolvimento dos trabalhos, visando à qualidade, à segurança e ao vínculo de confiança e empatia que permite relações de via de mão dupla. Assim, fortalecer e aprimorar o padrão de comunicação na saúde, criando interfaces, conexões e redes, é uma necessidade premente. 
No que se refere ao caso descrito neste artigo, ressaltaremos a importância da comunicação nos seguintes níveis: a) comunicação dialógica e relacional; b) comunicação organizacional (interna e externa); c) comunicação pública.

Kunsch (2012, p. 21), ao se referir a uma "comunicação organizacional", considera primeiro que ela abrange todos os tipos de organizações - públicas, privadas ou do terceiro setor. Ela lida com tudo que está implicado no contexto comunicacional das organizações: redes, fluxos, processos etc.

Para Freitas (2006, p. 57-58), a comunicação tem um papel de extrema relevância e abrangência, pois estabelece o diálogo na organização ou instituição. No âmbito interno, o diálogo se estabelece em consonância com a cultura institucional. No âmbito externo, ele é o reflexo da cultura da instituição. Assim, a comunicação ganha espaço como ativo intangível para melhorar os relacionamentos, pois possibilita a construção, manutenção e preservação da identidade e reputação de uma organização ou instituição, à medida que cuida da imagem a ser formada por todo e qualquer público, em todo e qualquer ponto de contato com a organização ou instituição.

Assim sendo, a forma como a organização ou instituição se relaciona e se comunica com seus diversos públicos irá influir na sua cultura e vice-versa. Em outras palavras, como define Weber (2009, p. 71), "a comunicação organizacional é 0 resultado de todas as ações institucionais, apoio, visibilidade e imagem pública".

Haswani (2011, p. 86) ressalta que a comunicação pública "não se refere somente ao âmbito dos atos normativos, mas também às iniciativas voltadas a favorecer a relação entre cidadãos e instituições, a promover as iniciativas e os serviços oferecidos, assim como valores e imagens de interesse geral".

Tratando-se de uma instituição pública os profissionais devem ter sempre em mente que estão diante de um usuário, um paciente, porém, acima de tudo, estão diante de um cidadão que, entre seus vários direitos, tem direito à informação, a orientação, de manifestar sua opinião e de participar das decisões que lhe dizem respeito.

Segundo a Política Nacional de Humanização, tais direitos se consolidam por meio da gestão participativa, pela qual a voz do usuário é o fio condutor para que se desenvolvam ações de melhoria e correções de curso das ações visando à qualidade. Por isso, é importante que canais de comunicação estejam sempre à disposição do usuário para ele se expressar, tais como ouvidoria, caixa de sugestão, pesquisa de satisfação, entre outros.

Na mesma linha de raciocínio, Matos (1999, p. 2-3) define a comunicação pública como "aquela que envolveria o cidadão de maneira mais diversa, participativa, estabelecendo um fluxo de relações comunicativas entre o Estado e a sociedade".

Podemos ressaltar que o compromisso e a qualidade do serviço prestado à sociedade é responsabilidade de todos e de cada um de nós. As instituições públicas podem e devem buscar parcerias da sociedade civil, com o propósito de fortalecer suas ações e boas práticas, porém, para que isto ocorra, a instituição deve atuar com transparência, fazendo a devida divulgação do trabalho desenvolvido e de suas necessidades. A política de humanização incentiva tais parcerias com a sociedade, associações e organizações não-governamentais.

A Política Nacional de Humanização recomenda que a comunicação na instituição pública ocorra de forma transversal, atingindo todos os segmentos institucionais com o mínimo de ruído possível, em um modelo de rede colaborativa. Para tanto, é necessário que se faça uso de todos os canais de comunicação disponíveis. Entretanto, promover tal comunicação 
transversal não é nada simples, exigindo pleno apoio da alta administração, além de, muitas vezes, para tornar-se viável, precisar de um alinhamento com o modelo tradicional de comunicação informacional adotado na instituição.

Para exemplificar o descrito acima, faremos uma breve apresentação do trabalho que envolveu a criação de um plano de ação para a implantação do serviço de "Acolhimento com Classificação de Risco no Pronto-Socorro do HU-USP". 0 caso em questão é de um hospital público, em que a comunicação pública se faz necessária e obrigatória, privilegiando princípios de transparência, segurança e qualidade do atendimento ao cidadão.

Esse serviço foi criado em decorrência do aumento expressivo da demanda de pacientes no pronto-socorro e do crescimento de queixas enviadas à Ouvidoria. Após meses de observação do local, coleta de dados quantitativos e qualitativos junto aos profissionais locais e reuniões com as equipes envolvidas, o serviço foi desenhado e implantado. Definiu-se como objetivo atender prontamente os pacientes classificados como graves, usando um protocolo de classificação de risco, ou seja, desta maneira, o atendimento aos pacientes deixou de ser por ordem de chegada, passando a ser por gravidade da queixa. Como essa mudança na porta de entrada do hospital poderia acarretar um grande impacto na opinião da população, até então acostumada com o modelo anterior, observou-se a necessidade de investir fortemente em ações de comunicação institucional. Inicialmente, o público-alvo atingido pelas ações de comunicação foi o público interno, posteriormente o público externo, pois ambos deveriam ser orientados.

No caso apresentado, do HU-USP, o uso e aprimoramento dos canais de comunicação teve o propósito de: a) melhorar a comunicação relacional; b) informar, orientar, construir e desconstruir paradigmas; c) aproximar as pessoas (público interno/externo) em movimento coletivo de mudança; d) divulgar, compartilhar e replicar as boas práticas, fazendo uso da técnica do benchmarking; e) captar incentivos financeiros e parcerias com instituições, organizações e sociedade em geral.

Os canais de comunicação utilizados foram: HU em Foco (informativo impresso e digital); vídeo explicativo; comunicação visual (quadro de sinalização); Jornal do HU (circulação interna/externa); o trabalho da Equipe de Acolhimento orientando o usuário e apresentando fôlder explicativo; mídia de massa (radio e televisão).

\section{O caso do Hospital Universitário da USP (HU-USP): caracterização}

Ligado a uma das maiores universidades do país, o HU-USP' está calcado no tripé ensino/pesquisa/assistência. É um hospitalescola, regional e de nível secundário, ou seja, destina-se a desenvolver atividades assistenciais e educacionais nas quatro especialidades básicas em saúde: clínica médica; clínica ginecológica e obstétrica; clínica pediátrica; e clínica cirúrgica. 0 desenvolvimento das atividades institucionais é fomentado com recursos da USP e complementado com recursos do Sistema Único de Saúde (SUS), através de convênio firmado com a Secretaria de Estado da Saúde do Estado de São Paulo.

O HU-USP somava 2.090 profissionais, dos quais 1.748 eram servidores da USP e 342, funcionários de empresas terceirizadas, segundo informações do Serviço de Pessoal do HU-USP. Na atuação acadêmica, no ano 2013, passou por

$\overline{1 \text { Sobre o HU-USP }}$, ver. seu portal: <http://www.hu.usp.br>. 
estágio no hospital um total de 2.767 alunos nos níveis de graduação, residência e complementação especializada. Em relação às pesquisas, foram realizadas cerca de oitenta, conforme a Comissão de Ensino e Pesquisa do HU-USP. No que se refere à assistência, no ano de 2013, o HU-USP realizou em média: 281.030 atendimentos no pronto-socorro; 154.850 atendimentos no ambulatório; 12.762 internações; 5.159 cirurgias; 3.520 partos; e mais de 1 milhão de exames diagnósticos, de acordo com Serviço de Arquivo Médico e Estatística do HU-USP.

Para as finalidades da humanização, consideram-se como públicos estratégicos e possíveis agentes multiplicadores de informação os colaboradores e alunos, na expectativa de pulverizar com seus princípios a instituição, como também toda a rede de assistência à saúde da região na qual os alunos irão atuar.

Com esse propósito, em 2010 foram iniciados no HU-USP os trabalhos seguindo a recomendação da Política Nacional de Humanização e em 2011 foi oficialmente criado o Serviço de Humanização para assessorar a alta administração nos assuntos referentes à humanização no ambiente hospitalar. Esse serviço desenvolveu suas atividades enfatizando a missão institucional e 0 alinhamento às diretrizes da Rede Humaniza FMUSPHC, bem como às políticas nacional e estadual de humanização. Eram três frentes de atuação: a) pesquisa de satisfação do usuário; b) gestão da equipe de acolhimento no pronto-socorro; c) desenvolvimento de projetos e ações de humanização, além do apoio a diversas áreas do hospital, monitoramento e registro de ações existentes. 0 objetivo geral foi disseminar o conceito e auxiliar no desenvolvimento da cultura da humanização no hospital, tendo como objetivos específicos: a) disseminar o conceito, a metodologia e o dispositivo recomendado pelas políticas de humanização nacional e estadual; b) refletir e conscientizar sobre a importância do modelo de gestão participativa; c) fazer diagnóstico situacional e propor planos de ação/projetos para sua melhoria; d) trabalhar com métodos que permitissem a participação das pessoas em interação; e) ser um catalisador das iniciativas de humanização existente, fortalecer, articular e comunicar, auxiliando no registro e ampliar a divulgação; f) auxiliar as diversas áreas no desenvolvimento de novos projetos; g) monitorar as ações e os projetos de humanização por meio de indicadores.

Inicialmente o trabalho do Serviço de Humanização deu-se em torno da sensibilização do público interno e da construção de espaços de diálogo e reflexão sobre o tema humanização em saúde, como também da apresentação das boas práticas existentes no hospital. Em 2011, realizou-se o I Workshop de Humanização do HU-USP, no qual se conseguiu agregar profissionais de diversas áreas da instituição e palestrantes renomados nessa temática. A experiência de 68 trabalhos desenvolvidos no hospital foi apresentada em forma de pôster, como também os trabalhos desenvolvidos por alunos nas Unidades Básicas de Saúde (UBS) da região, dando maior visibilidade aos trabalhos de referência.

Para auxiliar na sensibilização e pulverizar a instituição com informação sobre a humanização em diversos âmbitos, alguns canais de comunicação foram utilizados: questionário, rodas de conversa, reuniões administrativas, fôlder informativo, banner, kit informativo, Jornal do HU-USP, redes sociais, oficinas, workshop etc. Essas ações, além de auxiliarem como multiplicadoras de conhecimento e informação, contribuíram na formação de apoiadores de humanização, como também geraram importantes indicadores para desenvolver novas iniciativas. Foi criada uma peça de comunicação com abordagem lúdica e também como uma "provocação", para aguçar a curiosidade das pessoas sobre o tema: um protótipo de caixa de remédio com o nome "Humanização como remédio", contendo em sua parte interna uma bula com breve histórico e recomendações (Figura 1). 
Figura 1: Caixa "Humanização como remédio"

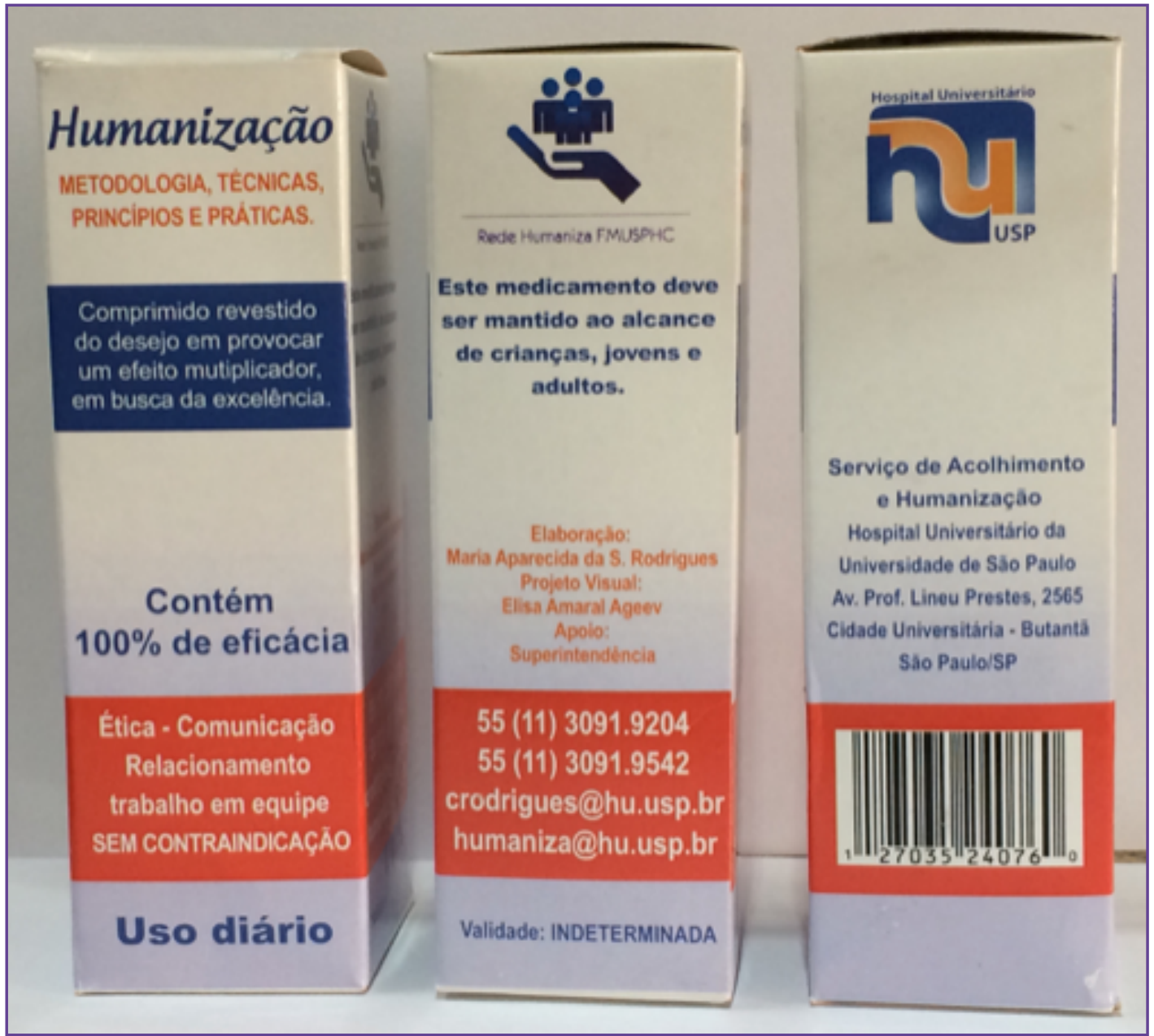

Elaboração: Maria Aparecida da Silva Rodrigues.

Projeto visual: Elisa Amaral Ageev.

No mesmo ano (2011) o Serviço de Humanização atuou com a alta administração e diversas áreas do hospital em reuniões de discussão para análise, alinhamento e desenvolvimento de ações para implantação do acolhimento com classificação de risco - utilizando o Protocolo de Manchester. Paralelamente a esse trabalho, recebeu a incumbência de desenvolver um Projeto de Acolhimento para o Pronto-Socorro que depois de concluído e aprovado foi implantado, contendo as seguintes ações de humanização:

1) Construção de uma nova ferramenta para pesquisa de satisfação do usuário: o instrumento foi desenvolvido pelo Serviço de Humanização com o apoio de gestores das áreas de Enfermagem, Serviço Social, Serviço de Zeladoria, Comunicação, Divisão de Nutrição e Dietética e Divisão de Laboratório Clínico;

2) Fornecimento de refeição para os acompanhantes de pacientes que permanecem na Observação por mais de 24 horas: após levantamento de dados estatísticos e diálogo com profissionais do Pronto-Socorro verificou-se que 0 custo seria baixo frente ao grande benefício recebido pela implantação dessa ação, visto que manter por todo 0 tempo a presença do acompanhante irá auxiliar no bem-estar e recuperação do paciente, como também contribuir com os profissionais na rotina diária;

3) Criação de espaço reservado para a sala de internação e alta hospitalar: com objetivo de proporcionar um ambiente confortável, climatizado e acolhedor, possibilitando a interação entre profissionais, pacientes e familiares; 
4) Criação da Equipe de Acolhimento: teve como objetivo atuar com foco na comunicação relacional, em informação e direcionamento de fluxo a usuários que chegam ao hospital para atendimento no Pronto-Socorro e no Ambulatório, exames e visitas a pacientes internados. A capacitação da equipe ocorreu por dois anos consecutivos (2012 e 2013). Em 2012 o treinamento foi realizado para Equipe de Acolhimento e em 2013 ele foi expandido, incluindo profissionais do Serviço de Arquivo Médico e Estatística (Same) e lideranças do Serviço de Zeladoria, profissionais que atuam na linha de frente.

Com o objetivo de disseminar conceitos e práticas da humanização, que devem ser indissociáveis das atividades de ensino e pesquisa, nos anos 2012 e 2013 o serviço recebeu alunos de várias unidades da USP, das áreas da saúde, administração, arquitetura, educação, entre outras, interessados em realizar visita monitorada e conhecer as ações de humanização existentes. Salientamos que a atuação nessa interface é de grande valor, pois estreita os laços com outras áreas, fortalece vínculos e, principalmente, promove trocas de informação e experiência, despertando nos alunos a sensibilidade para questões de saúde pública.

Com a crise que vive o país e as dificuldades econômicas que a saúde pública enfrenta, sensibilizar a sociedade para os problemas públicos pode ser um caminho para o movimento coletivo em prol de melhorias. A busca constante por apoiadores faz parte da nossa missão. Assim, contamos, por exemplo, com: a) equipe de 53 voluntários que auxiliam no acolhimento a pacientes e familiares; b) professores e alunos da Faculdade de Arquitetura e Urbanismo da USP (FAUUSP), que contribuíram na revitalização do espaço físico e no novo projeto de comunicação visual do Ambulatório e do Pronto-Socorro; c) doações, como um piano da Escola de Comunicações e Artes (ECA-USP), usado na organização de um espaço de convivência para usuários, funcionários, estudantes e visitantes; d) treinamento comportamental para os funcionários do hospital, desenvolvido pela Associação Arte Despertar.

Acreditamos que atuar com objetividade e transparência, definindo precisamente objetivos, propostas, projetos e ações de humanização, assim como prestando contas dos resultados obtidos, nos ajudou na captação de parcerias.

Inicialmente, o Serviço de Humanização atuava com duas profissionais em dedicação integral na instituição como um todo, além de fazer a gestão da Equipe de Acolhimento no Pronto-Socorro. Porém, com o decorrer dos meses, houve a necessidade de ampliação dos trabalhos e, com objetivo de intensificar as ações, em novembro de 2013, por meio da Portaria HU-S 779/13, foi criado o Grupo de Trabalho de Humanização (GTH-HU), como equipe multidisciplinar que se reúne quinzenalmente com 0 objetivo de analisar questões relacionadas com a temática, tornando-se agentes multiplicadores da política de humanização.

Como ponto de partida para o trabalho do GTH-HU, a coordenação propôs realizar um mapeamento das ações de humanização no hospital, como forma de fazer um diagnóstico situacional. A proposta de mapear todas as áreas da instituição, por meio de visita técnica, teve o intuito de verificar como os profissionais compreendem a humanização, promover a cultura da humanização, traduzindo-a em uma linguagem mais homogênea, como também realizar captura e registro das ações de humanização existentes, incentivando o uso de indicadores. Para auxiliar o grupo nas atividades e na disseminação da proposta, foi montado um kit informativo - material impresso entregue à chefia de cada área visitada - e, fazendo uso do espaço on-line, se criou o hotsite www1.hu.usp.br/humaniza. Para esse trabalho utilizou-se a metodologia elaborada e publicada no Guia Técnico-Político para o Desenvolvimento da Humanização das Práticas de Saúde(HCFMUSP, 2014). O mapeamento como primeira fase do plano de trabalho foi um trabalho coletivo com resultados expressivos, conforme pode ser verificado no Gráficol, mais adiante. 
Manter registradas as iniciativas com caráter humanizador existentes é relevante, porque: a) promove a divulgação interna e, quando necessário, replica as ações; b) promove o registro contínuo da produtividade do hospital no que se refere à humanização, agregando valor aos profissionais que desenvolvem as ações; c) cria banco de dados e as informações armazenadas são disponibilizadas e encaminhadas às áreas sempre que solicitado; d) faz parte do plano operativo e de metas pactuado entre a Secretaria de Estado da Saúde e o Hospital Universitário (Portaria Interministerial n. 2.400, de 2 de outubro de 2007, art. $7^{0}$, parágrafo XV), pois a cada quatro meses uma planilha com descritivo das ações deve ser encaminhada à Secretaria, através do relatório SAHE - Sistema de Avaliação de Hospital de Ensino, resultando em incentivo financeiro (Brasil, 2007); d) permite acompanhar o desenvolvimento da cultura da humanização na Rede Humaniza FMUSPHC, possibilitando ampliar a divulgação das ações na rede do sistema de saúde.

\section{A REDE HUMANIZA FMUSPHC}

0 trabalho desenvolvido em rede, segundo recomendação da Política Nacional de Humanização, é importante dispositivo para gerar engajamento das pessoas de forma sinérgica. Levando-se em consideração essa recomendação, em 2010 foi criada a Rede Humaniza FMUSPHC e em 2012, o Núcleo Técnico de Humanização (NTH) - instância coordenadora -, com representantes de dezesseis serviços de saúde: Instituto de Medicina de Reabilitação/Rede Lucy Montoro (IMREA/RRLM); Instituto de Psiquiatria (IPq); Instituto do Coração (InCor); Instituto Cetral (ICHC); Instituto de Ortopedia e Traumatologia (IOT); Instituto de Radiologia (InRad); Instituto da Criança (ICr); Instituto do Câncer do Estado de São Paulo (Icesp); Hospital Auxiliar de Cotoxó (HAC); Hospital Auxiliar de Suzano (HAS); Laboratórios de Investigação Médica do HC (LIM); Gestão da Região Oeste (PRO); Prédio da Administração do HC (PA); Pronto-Socorros; Hospital Universitário (HU); e Centro de Saúde Escola do Butantã (CSE). Os representantes se reúnem a cada quinze dias para realizar trocas, compartilhar ideias, propostas de trabalho².

A atuação no formato de rede com as instituições parceiras com o qual o HU-USP se relaciona, como é o caso do modelo da Rede HumanizaFMUSPHC, amplia o diálogo na possibilidade de estreitar os laços, pulverizar e fortalecer a humanização no sistema de saúde da região.

O Núcleo Técnico de Humanização (NTH) na Rede HumanizaFMUSPHC funciona como um catalisador de energia em movimento coletivo, promove a integração dos coordenadores da humanização dos vários serviços de saúde, um aprendizado contínuo. Abre portas para trocas de experiências, auxiliando no desvendar das dificuldades e novas possibilidades de atuação, promovendo a celebração de alianças estratégicas com a finalidade de adquirir competências e sempre respeitando a singularidade de cada serviço. Esse modelo de atuação, propiciando o compartilhamento de boas experiências, se assemelha à técnica do benchmarking utilizada nas empresas no processo de busca das melhores práticas, considerada uma técnica que apresenta resultados efetivos.

A literatura traz diversos tipos de benchmarking. Camp (1998, p. 53-57) cita os seguintes: o interno, o competitivo, o funcional e o genérico. Para efeito deste artigo, em função do modelo de rede citado acima, será considerado o benchmarking funcional, pois no caso que estamos estudando não existe a ideia de concorrência. 0 foco está em identificar técnicas interessantes adotadas por empresas tidas como excelentes, porém não necessariamente concorrentes. É um processo de descoberta e de uma experiência de aprendizagem. Exige a identificação das melhores práticas e a projeção do desempenho futuro. Nunca serão "cópias", pois haverá sempre ajustes, adaptação e aprimoramentos, o que garante a "evolução" da ideia original.

2 Cf. Guia técnico-politico para o desenvolvimento da humanização das práticas de saúde (HCFMUSP, 2014, p.5-7). 
Outra técnica que podemos considerar é a do benchmarking interno, desenvolvido dentro da própria empresa. 0 que se espera com essa prática é identificar dentro da organização as melhores práticas, com o objetivo de disseminá-las por todas as áreas. Tem como vantagens a facilidade para angariar parcerias, custos mais baixos e a valorização do pessoal interno. É tanto uma forma de busca de melhorias, quanto uma oportunidade de autoconhecimento para uma organização (Camp, 1998, p. 53-54). Está nisso o propósito do mapeamento realizado pelo GTH-HU.

\section{RESULTADO - MAPEAMENTO COMO DIAGNÓSTICO E FERRAMENTA DE COMUNICAÇÃO}

Não é tarefa fácil gerenciar todo o processo da humanização, pois se está atuando em campos de subjetividades, dimensão intangível, mas que muitas vezes é colocada em xeque. Na gestão da humanização, tornar o intangível quantificável é o grande desafio. Faz-se necessário apresentar o resultado em números, de forma a agregar valor aos profissionais que desenvolvem os projetos/ações, como também à instituição. 0 resultado das ações de humanização muitas vezes se apresenta de forma discreta e imperceptível aos olhos da alta administração. Assim, tornar palpável o resultado possibilita evidenciar o impacto na qualidade e na melhoria dos processos.

Abaixo (Gráfico 1) se apresenta o resultado do mapeamento realizado no período que compreende do quarto trimestre de 2013 ao terceiro quadrimestre de 2014. Cabe ressaltar que até o ano 2013 a compilação dos dados era realizada e encaminhada para a Secretaria de Estado da Saúde do Estado de São Paulo e a Rede Humaniza FMUSPHC a cada três meses. A partir de 2014, o resultado consolidado das ações de humanização passou a ser encaminhado a cada quatro meses.

Gráfico 1: mapeamento das ações de humanização no HU-USP.

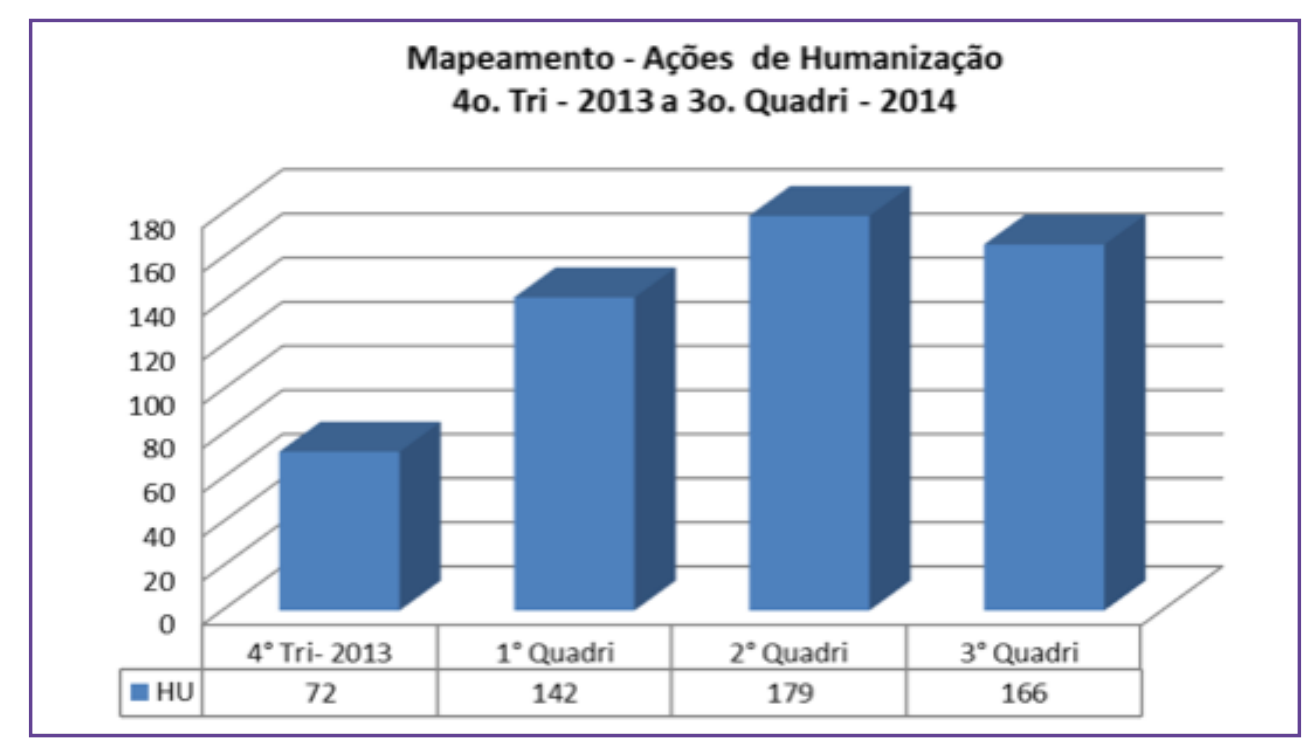

Fonte: HCFMUSP , 2014.

O crescente aumento registrado, das iniciativas de humanização, é resultado do trabalho do GTH-HU no mapeamento como diagnóstico institucional, da disseminação das diretrizes da humanização conforme modelo da Rede HumanizaFMUSPHC, como também da compreensão da percepção da humanização por parte dos funcionários. Esse processo inicial ofereceu um extenso, trabalhoso e rico material para reflexão, análise e reconhecimento das várias iniciativas de humanização desenvolvidas no hospital, que podem ser replicadas de forma interna e externa à instituição. Verificou-se que a maior parte das ações ocorre de forma contínua, porém muitas são desconhecidas pelo público interno em geral. A solicitação 
de registro e encaminhamento das ações ao GTH-HU foi considerada por alguns funcionários como aumento de trabalho, porém, após orientação e apresentação de sua importância, a tarefa foi incorporada na rotina.

\section{CONSIDERAÇÕES FINAIS}

A relevância da humanização no ambiente corporativo é tema abordado há décadas pelos mais variados nichos de mercado na sociedade contemporânea, que em comum ressaltam a importância de lançar olhar para as pessoas e os grupos em interação, produzindo espaços que promovam processos de trabalho criativos e resolutivos, contribuindo para a qualidade de serviços e produtos. No âmbito hospitalar, a relevância dessa interação tende a impactar no cuidado com o outro (colaborador ou usuário) em prol da excelência na qualidade da assistência.

0 exercício da gestão participativa em instituições onde prevalece o modelo tradicional é um grande desafio, por encontrar muitas resistências. Dessa forma, faz-se necessário o apoio da alta administração de forma efetiva para promover ações institucionais contínuas, de forma transversal, envolvendo gestores, profissionais e usuários. Tratando-se de um processo de mudança de cultura, buscar um ponto de equilíbrio entre os dois modelos de gestão - o tradicional e mais antigo e 0 participativo e mais alinhado à humanização - poderá ser o caminho para o desenvolvimento da instituição como um todo.

No caso em estudo, por se tratar da humanização enquanto política pública de saúde, o desenvolvimento da gestão de humanização requereu sua formatação como política institucional e legitimada, gerando empoderamento e viabilizando maior flexibilidade de atuação ao Grupo de Trabalho de Humanização. 0 reconhecimento da importância do trabalho desenvolvido em rede colaborativa permite estreitar os laços com outros serviços, como também fortalecer a humanização na rede de atenção à saúde, conforme recomenda a Política Nacional de Humanização - HumanizaSUS.

0 resultado do mapeamento realizado pelo GTH-HU mostrou um cenário de grande investimento por parte de profissionais e grupos em ações para melhoria local, mas o que chamou a atenção foi o desconhecimento de muitas ações por parte do público interno, o que nos leva a considerar que possivelmente o modelo fragmentado de gestão institucional ainda prevalece.

Desenvolver iniciativas institucionais que promovam a interação, a ampla disseminação das boas práticas com caráter humanizador existentes e fortaleçam o incentivo de novas práticas que podem ser replicadas, contribuindo com áreas internas e serviços externos à instituição, certamente irá agregar valor aos profissionais e grupos que as desenvolvem, como também irá auxiliar no fortalecimento da reputação e imagem positiva da instituição. Bueno (2010) ressalta que a reputação é um dos atributos da imagem. É o valor que está presente na forma pela qual indivíduos, grupos ou a opinião pública contemplam uma organização. A imagem é um dos ativos intangíveis mais valorizados no mundo moderno. Retrata a identidade corporativa, ou seja, o que ela é, o que faz e o que diz. Como forma de aferir a percepção que os públicos têm das organizações, o autor recomenda a realização de auditoria de imagem.

As análises apresentadas neste artigo reafirmam a necessidade de promover um trabalho de humanização integrado e com maior investimento em ações como: a) sensibilizar gestores e funcionários; b) criar estratégias de ampliação de espaço para discussão e interação; c) criar informativos periódicos possibilitando um fluxo de informação mais dinâmico e outras formas de comunicação, como estratégias para o desenvolvimento da humanização nos serviços de saúde, tendo como resultado o impacto na imagem positiva da instituição, sendo a humanização também uma vitrine das suas boas práticas. 


\section{REFERÊNCIAS}

BRASIL. Ministério da Educação e Cultura e Ministério da Saúde. Portaria Interministerial MEC/MS n. 2.400, de 2 de outubro de 2007. Disponível em: <dtr2001.saude.gov/sas/PORTARIAS/Port2007/GM/GM-2401.htm>. Acesso em: 23 jun. 2015.

Ministério da Saúde [on-line]. Política Nacional de Humanização Hospitalar. Brasília: MS, 2003. Disponível em: $<$ www.saúde.gov.br/>.

. Política Nacional de Humanização (PNH). HumanizaSUS - Documento - Base 3. Brasília: MS, 2006.

BUENO, Wilson da Costa. Auditoria de imagem na midia. In: DUARTE, Jorge; BARROS, Antonio T. (Orgs.). Métodos e técnicas de pesquisa em comunicação. 2. ed. São Paulo: Atlas, 2010. p. 345-363.

CAMP, Roberto C. Benchmarking: o caminho da qualidade total. 3. ed. São Paulo: Pioneira, 1998.

CAMPOS, Gastão Wagner de Sousa. Humanização na saúde: um projeto em defesa da vida? Interface: Comunicação, Saúde e Educação, Botucatu, v. 9, n.17, p. 398-400, 2005.

CASTTELLS, Manuel. A sociedade em rede. Vol. 3. A era da informação, economia, sociedade e cultura. Rio de Janeiro: Paz e Terra, 1998.

CHIAVENATO, Idalberto. Abordagem humanística da administração. In: Introdução à teoria geral da administração: uma visão abrangente da moderna administração das organizações. 7. ed. - rev. e atual. Rio de Janeiro: Elsevier, p. 97-113, 2003.

DESLANDES, Suely Ferreira (Org.). Humanização dos cuidados em saúde: conceitos, dilemas e práticas. Rio de Janeiro: Fiocruz, 2006. p. 33-47.

FREITAS, Sidinéia Gomes de. Cultura organizacional e comunicação. In: KUNSCH, Margarida M. Krohling (Org.). Obtendo resultados com relações públicas. 2. ed - rev. e atual. São Paulo: Pioneira Thomson Learning, 2006, p. 53-62.

GOVERNO - Governo do Estado de São Paulo. Secretaria de Estado da Saúde (on-line). Política Estadual de Humanização PEH. Núcleo Técnico de Humanização. São Paulo: 2012. Disponível em: <http://www.saude.sp.gov.br/resources/humanizacao/ homepage/ acesso-rapido/politica_estadual_de_humanizacao_v5.pdf>.

HASWANI, Mariângela Furlan. Comunicação pública 360 graus e a garantia de direitos. In: KUNSCH, Margarida M. Krohling (Org.). Comunicação pública, sociedade e cidadania. São Caetano do Sul, SP: Difusão, 2011. p. 81- 97.

HCFMUSP - Hospital das Clínicas da Faculdade de Medicina da Universidade de São Paulo. Núcleo Técnico e Científico de Humanização. Guia técnico-político para o desenvolvimento da humanização das práticas de saúde. São Paulo: HCFMUSP, 2014.

KUNSCH, Margarida M. Krohling. A dimensão humana da comunicação organizacional. In: (Org.). A comunicação como fator de humanização das organizações. São Paulo: Difusão, 2010.

. Comunicação pública: direitos de cidadania, fundamentos e práticas. In: MATOS, Heloiza (Org.). Comunicação pública: interlocuções, interlocutores e perspectivas. São Paulo: ECA-USP, 2012. p. 13-29.

MATOS, Heloiza. Comunicação pública, democracia e cidadania: o caso legislativo. In: CONGRESSO BRASILEIRO DE CIÊNCIAS DA COMUNICAÇÃO, XXII, Rio de Janeiro, 06-09 set. Anais... São Paulo: Intercom, 1999. 
RIOS, Izabel Cristina. Caminhos da humanização na saúde: prática e reflexão. São Paulo: Aurea, 2009.

RIOS, Izabel Cristina; BATTISTELLA, Linamara Rizzo. Gestão da humanização das práticas de saúde: o Hospital das Clínicas da Faculdade de Medicina da Universidade de São Paulo. Saúde e Sociedade [on-line], São Paulo, v. 22, n. 3, p. 853-865, 2013.

RODRIGUES, Maria Aparecida da Silva. A importância da comunicação para a implementação da Política Nacional de Humanização no Hospital Universitário da Universidade de São Paulo. Organicom - Revista Brasileira de Comunicação Organizacional e Relações Públicas, São Paulo, ECA-USP, a. 9, n. 16/17, p. 182-198, 2012.

WEBER, Maria Helena. Comunicação organizacional, a síntese; relações públicas, a gestão estratégica. Organicom - Revista Brasileira de Comunicação Organizacional e Relações Públicas, São Paulo: ECA-USP; a. 6, n. 10/11, p. 70-75, 2009.

Texto recebido em 29.03.2017 e aprovado em 20.06.2017. 